\title{
PEMANFAATAN BIT.LY DALAM STRATEGI PEMBELAJARAN SIMULASI VIRTUAL UNTUK MENINGKATKAN PENGUASAAN KONSEP MOMENTUM, IMPULS, DAN TUMBUKAN
}

\author{
Asep Ilham Juliansyah ${ }^{1}$, Annisa Fitria Lukman², Nana ${ }^{3}$ \\ Pendidikan Fisika Fakultas Keguruan dan Ilmu Pendidikan. Universitas Siliwangi 2018 \\ E-mail : annisaflukman@gmail.com
}

\begin{abstract}
ABSTRAK - Penelitian ini menggunakan aplikasi bit.ly sebagai media dalam strategi pembelajaran menggunakan simulasi virtual bertujuan untuk meningkatkan penguasaan konsep momentum, impuls, dan tumbukan untuk mata pelajaran fisika SMA. Dalam proses pembelajaran, alokasi belajar siswa dibatasi atau dikontrol oleh tujuan-tujuan kurikuler dan kurikulum, materi atau bahan yang dipelajari perlu dipilih dan disesuaikan dengan tujuan tersebut. Pada saat inilah peran guru dan bahan ajar menjadi penting untuk memfasilitasi siswa baik di sekolah maupun ketika belajar di rumah. Dalam proses Pembelajaran penggunaan model pembelajaran di era modern memiliki beberapa ciri, diantaranya kegiatan pembelajaran dituangkan dalam teknologi, adanya asosiasi, kombinasi dari berbagai aspek, bahan bisa digunakan oleh individual atau kelompok. Di era modern ini tentu peserta didik sudah tidak asing dan familiar dengan penggunakan internet, pendidik dapat dengan mudah memberikan bahan ajar atau bahan tugas melalui internet pada peserta didik. Salah satunya adalah penggunaan bit.ly yang sudah cukup familiar di era modern ini. Selain itu, Strategi simulasi virtual yang digunakan dalam pembelajaran materi momentum, impuls, dan tumbukan dengan menggunakan aplikasi flash player sebagai media untuk simulasi virtual dapat membantu proses pembelajaran khususnya praktikum yang berbentuk virtual.
\end{abstract}

Kata Kunci : Strategi Pembelajaran simulasi virtual.

ABSTRACT - This study uses the bit.ly application as a media in learning strategies using virtual simulations to improve mastery of the concepts of momentum, impulses, and collisions for high school physics subjects. In the learning process, student participation learns or is controlled by curricular and curriculum objectives, the material or material being studied needs to be selected and adapted to that goal. At this time the role of the teacher and teaching material becomes important to facilitate students who are good at school and also study at home. In the learning process using the learning model in the modern era has several characteristics, the contribution of learning activities is outlined in technology, association participation, a combination of various aspects, materials can be used by individuals or groups. In this modern era students are certainly no strangers and familiar with the use of the internet, educators can easily provide teaching materials or assignments through the internet to students. One of them is the use of bit.ly which is already quite familiar in this modern era. In addition, the virtual simulation strategy used in the learning material of momentum, impulses, and using the flash player application as a medium for virtual simulation can help the learning process specifically form practicum virtual.

Keywords: Learning Strategy virtual simulation. 


\section{Pendahuluan}

Fisika merupakan salah satu bagian dari Ilmu Pengetahuan Alam. Karakter materi fisika bersifat konkret, namun ada pula yang bersifat abstrak. Salah satu materi fisika yang bersifat abstrak adalah materi momentum, impuls, dan tumbukan. Hal ini dikarenakan materi tersebut terjadi dalam waktu yang sangat singkat dan cepat. Materi yang bersifat abstrak ini mengakibatkan siswa kesulitan untuk memahami konsep momentum. (Sa'idah, Prihandono, Wahyuni, 2018).

Praktikum atau eksperimen merupakan metode pembelajaran yang selalu dilakukan dalam pembelajaran IPA khususnya Fisika. Di era revolusi 4.0 ini, hampir $90 \%$ proses pembelajaran menggunakan teknologi. Salah satu upaya teknologi untuk memudakan pendidik dalam memberikan tugas kepada peserta didik adalah menyiapkan bahan tugas yang akan diberikan dalam bentuk surel yang kemudian dapat di akses oleh peserta didik. Salah satu pemanfaatan teknologi ini adalah pemanfaatan penggunakan bit.ly. Bit.ly merupakan layanan URL Shortener dan Link Management Platform yang memungkinkan untuk merubah URL yang panjang menjadi lebih ringkas dan juga menentukan nama yang lebih mudah diingat pada URL yang telah dipendekkan. Praktikum yang dilakukan di jaman modern ini juga dapat memanfaatkan teknologi.
Praktikum ini dinamakan praktikum virtual. Praktikum virtual merupakan proses pembelajaran elektronik dengan menggunakan simulasi komputer, seperti flash player. Kegiatan praktikum virtual dapat memfasilitasi siswa untuk meningkatkan penguasaan konsep dan keterampilan berpikir kritis peserta didik.

Momentum merupakan besaran vektor dan arahnya sama dengan arah kecepatan (v). Satuan momentum adalah satuan massa kali kecepatan gerak benda tersebut, dalam SI dinyatakan dengan $\mathrm{Kgms}^{-1}$. Semakin besar massa benda semakin besar momentumnya. Demikian pula jika semakin cepat benda bergerak semakin besar pula momentumnya. Sebuah truk bermuatan penuh akan lebih sulit untuk berhenti daripada mobil kecil, walaupun kecepatan kedua kendaraan itu sama. Kenapa demikian? Dalam pengertian fisisnya dikatakan bahwa momentum truk lebih besar daripada mobil. Secara fisika, pengertian momentum adalah hasil kali antara massa benda (m) dan kecepatannya (v), yang dituliskan sebagai berikut.

$$
p=m \times v
$$

$$
\begin{aligned}
& \text { Keterangan: } \\
& \mathrm{p}=\operatorname{momentum}(\mathrm{kg} \cdot \mathrm{m} / \mathrm{s} \text { atau Ns}) \\
& \mathrm{m}=\operatorname{massa}(\mathrm{kg}) \\
& \mathrm{v}=\operatorname{kecepatan}(\mathrm{m} / \mathrm{s})
\end{aligned}
$$


Seperti halnya energi mekanik, ternyata pada momentum berlaku hukum kekekalan, yang dinamakan Hukum Kekekalan Momentum. Hukum ini menyatakan bahwa "jika tidak ada gaya luar yang bekerja pada sistem, momentum total sesaat sebelum sama dengan momentum total sesudah tumbukan”. Ketika menggunakan persamaan ini, arah kecepatan tiap benda harus diperhatikan. Impuls merupakan hasil kali antara gaya konstan $\mathrm{F}$ dan interval waktu $\Delta t$ dengan waktu.

Impuls didefinisikan sebagai hasil kali antara gaya yang bekerja dengan selang waktu saat gaya tersebut bekerja pada benda. Impuls sama dengan perubahan momentum benda. Jadi impuls suatu benda dirumuskan sebagai berikut:

$$
I=F x \Delta t
$$

Keterangan:

$$
\begin{aligned}
& \mathrm{I}=\text { Impuls (Ns atau Kg.m/s) } \\
& \mathrm{F}=\text { Gaya yang bekerja pada }
\end{aligned}
$$

benda ( $\mathrm{N}$ atau $\left.\mathrm{Kg} . \mathrm{m} / \mathrm{s}^{2}\right)$

$\Delta t=$ Interval waktu selama benda

bekerja (s)

Dalam kehidupan sehari-hari, kita bisa menyaksikan benda-benda saling bertumbukan. Banyak kecelakaan di jalan raya sebagaimana disebabkan karena tabrakan (tumbukan) antara dua kendaraan, baik antara sepeda motor, mobil dengan mobil maupun sepeda motor dengan mobil. Dengan demikian, Tumbukan adalah pertemuan dua benda yang relatif bergerak.
Pada setiap jenis tumbukan berlaku hukum kekekalan momentum tetapi tidak selalu berlaku hukum kekekalan energi mekanik. Tumbukan antara benda disebut tumbukan lenting sempurna jika momentum dan energi kinetik masing-masing benda sebelum tumbukan sama dengan momentum dan energi kinetik masingmasing benda setelah tumbukan. Pada tumbukan lenting sebagian (tumbukan lenting tidak sempurna) berlaku hukum kekekalan momentum sedangkan hukum kekekalan energi kinetik tidak berlaku. Selama terjadi tumbukan, sebagian energi kinetik berubah menjadi energi bunyi, energi panas dan energi dalam. Dalam setiap tumbukan antara dua benda atau lebih, hukum kekekalan momentum selalu berlaku selama tidak ada gaya luar yang bekerja pada sistem. Namun demikian, energi kinetik sistem sebelum dan sesudah tumbukan terjadi tidak sama.

\section{Metode Penelitian}

Penelitian ini menggunakan metode eksperimen dan literasi (studi pustaka) sebagai penguat dari eksperimen yang telah dilakukan dengan cara mengkaji berbagai literatur yang berkaitan dengan penerapan model POE2WE dalam era Revolusi 4.0 yang menghasilkan produk berupa modul momentum, impuls, dan tumbukan dengan strategi pembelajaran simulasi virtual dengan menggunakan Flash Player. Penelitian ini bertujuan untuk 
mengamati kemampuan dan keterampilan peserta didik dalam memahami konsep momentum, impuls, dan tumbukan melalui praktikum virtual menggunakan animasi flash player.

Penelitian ini dilaksanakan di Jurusan Pendidikan Fisika 2019 Universitas Siliwangi pada mata kuliah Fisika Sekolah. Sampel yang digunakan berasal dari Mahasiswa yang mengikuti perkuliahan dan bertindak sebagai peserta didik (subjek peneliti).

Analisis data yang digunakan adalah analisis deskriptif dengan pendekatan kuantitaif yang menghasilkan kriteria keefektifan dari data kuantitatif instrumen eksperimen. Analisis data dalam penelitian ini dimaksudkan untuk mendeskripsikan keefektifan penggunakan bit.ly dan simulasi virtual pada pembelajaran momentum, impuls, dan tumbukan Fisika SMA.

\section{Alat dan bahan}

Dalam percobaan ini, menggunakan alat peraga berbentuk perangkat lunak atau software komputer berbasis animasi flash player berupa simulasi tumbukan. Berikut alat dan bahan yang dibutuhkan, antara lain: (a) Komputer atau Laptop, (b) Seperangkat simulasi interaktif dari animasi flash player yang terdiri dari alat-alat bantu berupa dua buah bola, massa kedua benda, kecepatan kedua benda, dan koefisien restitusi (e) untuk materi tumbukan.

\section{Prosedur kerja}

(1)Peserta didik membuka beranda internet dan membuka https://bit.ly/363Ikd5 untuk mengunduh bahan praktikum virtual. (2) Membuka bahan yang telah diunduh. (3) Menentukan pengaruh massa dan kecepatan pada dua buah bola terhadap koefisien restitusi. (4) Tentukan massa dan kecepatan kedua benda yang akan diamati. (5) Pastikan koefisien restitusi sesuai dengan konsep tumbukan yang telah dipelajari. Seperti tumbukan lenting sempurna dengan nilai restitusi 1 , tumbukan lenting sebagian dengan nilai restitusi 01 sampai 0,9, dan tumbukan tidak lenting sama sekali memiliki nilai restitusi sama dengan nol. (6) Langkah 1 dan 2 dapat dilakukan dengan mengamati peristiwa tumbukan pada satu buah bola yang memantul ke sebuah dinding. (7) Amati dan catat hasil yang tercantum padaflash player.

Gambar 1. Penggunaan simulasi virtual untuk materi tumbukan

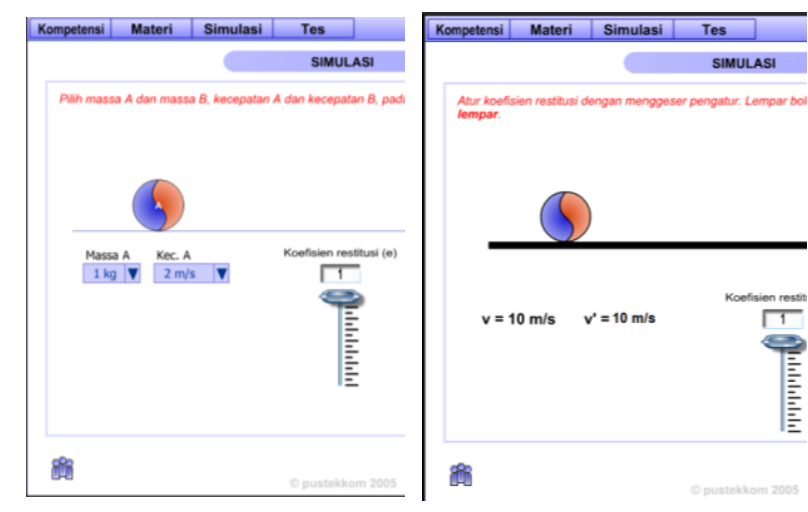

Dengan melakukan simulasi virtual ini peserta didik diharapkan mampu menjawab beberapa pertanyaan, diantaranya: (1) Bagaimana 
pengaruh massa terhadap dua benda yang saling bertumbukan, (2) Bagaimana pengaruh kecepatan terhadap dua benda yang saling bertumbukan, (3) Jelaskan perbedaan tumbukan berdasarkan koefisien restitusi yang digunakan, (4) Apa saja yang mempengaruhi benda mengalami peristiwa tumbukan lenting sempurna, tumbukan lenting sebagian, dan tumbukan tidak lenting sama sekali.

Analisis data dalam penelitian ini dimaksudkan untuk mendeskripsikan keefektifan simulasi virtual sebagai alat bantu peraga praktikum materi momentum, impuls, dan tumbukan Fisika SMA.

Tabel 1. Skor kriteria penilaian keefektifan media untuk analisis desktiptif

\begin{tabular}{|c|c|l|}
\hline No & Skor & \multicolumn{1}{|c|}{$\begin{array}{c}\text { Keterangan penggunaan dan } \\
\text { pengaplikasian media }\end{array}$} \\
\hline 1 & 4 & $\begin{array}{l}\text { Sangat efektif/sangat mudah/sangat } \\
\text { baik }\end{array}$ \\
\hline 2 & 3 & Efektif/mudah/baik \\
\hline 3 & 2 & $\begin{array}{l}\text { Cukup efektif/cukup mudah/cukup } \\
\text { baik }\end{array}$ \\
\hline 4 & 1 & $\begin{array}{l}\text { Tidak efektif/tidak mudah/tidak } \\
\text { baik }\end{array}$ \\
\hline
\end{tabular}

\section{Hasil Penelitian dan Pembahasan}

Pemanfaatan simulasi virtual dalam pembelajaran materi momentum, impuls dan tumbukan menggunakan aplikasi bit.ly untuk meningkatkan penguasaan konsep materi melalui penugasan dihasilkan data penelitian dari sampel yang digunakan terkait keefektifan penggunaan simulasi virtual sebagai alat bantu peraga pendidik untuk peserta didik.

\section{Tabel 2. Tahapan Penelitian.}

\begin{tabular}{|c|c|}
\hline Tahap Penelitian & Kegiatan yang dilakukan \\
\hline $\begin{array}{l}\text { Sebelum } \\
\text { Penelitian }\end{array}$ & $\begin{array}{l}\text { - Pembentukan tim partisipatif } \\
\text { (terdiri dari Dosen Ahli } \\
\text { sebagai validator dan } \\
\text { mahasiswa sebagai objek } \\
\text { penelitian). } \\
\text { - Penyusunan instrumen } \\
\text { penelitian berupa ekserimen } \\
\text { yang dilakukan oleh subjek } \\
\text { peneliti dalam menggunakan } \\
\text { bit.ly dan simulasi virtual } \\
\text { materi pelajaran momentum, } \\
\text { impus, dan tumbukan dan } \\
\text { penyaji bertindak sebagai } \\
\text { pendidik dan subjek peneliti } \\
\text { sebagaipeserta didik. }\end{array}$ \\
\hline $\begin{array}{l}\text { Pelaksanaan } \\
\text { Penelitian }\end{array}$ & $\begin{array}{l}\text { - Revisi instrumen. } \\
\text { - Validasi instrumen oleh ahli. } \\
\text { - Uji coba produk. }\end{array}$ \\
\hline $\begin{array}{l}\text { Setelah } \\
\text { Penelitian }\end{array}$ & $\begin{array}{l}\text { - Penyusunan laporan daridata } \\
\text { yang telah diperoleh. }\end{array}$ \\
\hline
\end{tabular}

Kecenderungan keefektifan pelaksanaan pembelajaran dengan google classroom menggunakan subjek peneliti sebanyak 35 orang dapat disajikan dalam Tabel 3.

Tabel 3. Distribusi kecenderungan keefektifan pembelajaran simulasi virtual sebagai media pembelajaran. 


\begin{tabular}{|c|c|c|l|}
\hline Skor & Frekuensi & Persentase & \multicolumn{1}{|c|}{$\begin{array}{c}\text { Klasifikasi } \\
\text { penggunaan } \\
\text { media }\end{array}$} \\
\hline 4 & 7 & $20 \%$ & $\begin{array}{l}\text { Sangat } \\
\text { efektif/sangat } \\
\text { mudah/sangat } \\
\text { baik }\end{array}$ \\
\hline 3 & 12 & $34,3 \%$ & $\begin{array}{l}\text { Efektif/mudah/ } \\
\text { baik }\end{array}$ \\
\hline 2 & 9 & $25,7 \%$ & $\begin{array}{l}\text { Cukup } \\
\text { efektif/cukup } \\
\text { mudah/cukup baik }\end{array}$ \\
\hline 1 & 7 & $20 \%$ & $\begin{array}{l}\text { Tidak efektif/tidak } \\
\text { mudah/tidak baik }\end{array}$ \\
\hline Total & 35 & $100 \%$ & \\
\hline
\end{tabular}

Diagram 1. Presentasi keefektifan pembelajaran menggunakan simulasi virtual sebagai alat bantu praktikum materi momentum, impuls, dan tumbukan fisika SMA.

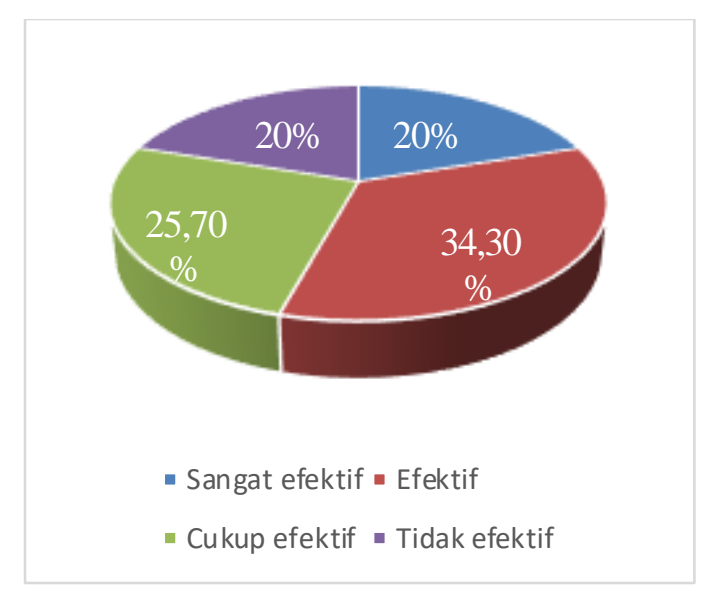

Berdasarkan data penelitian yang diperoleh melalui eksperimen kepada subjek peneliti ditujukan agar peneliti dapat mengukur sejauh mana persentase keefektifan dan keberhasilan penggunaan media bit.ly dan pemanfaatan simulasi virtual untuk mengingkatkan penguasaan konsep materi momentum, impuls, dan tumbukan pada mata pelajaran Fisika SMA. Data persentase di atas menyatakan bahwa responden penelitian $20 \%$ menyatakan bahwa pemanfaatan simulasi virtual sangat efektif digunakan di era teknologi ini apalagi jiga dibarengi dengan penggunaan bit.ly sebagai perantara antara pendidik dan peserta didik. $34,3 \%$ responden menyatakan bahwa penggunaan media ini efektif, 25,7\% menyatakan cukup efektif dan $20 \%$ menyatakan penggunaan media ini masih belum efektif jika diaplikasikan pada penerapan kurikulum Indonesia yang belum merata di setiap daerahnya.

\section{Kesimpulan}

Simpulan yang diperoleh dari penelitian menggunakan aplikasi bit.ly sebagai media dalam strategi pembelajaran menggunakan simulasi virtual bertujuan untuk meningkatkan penguasaan konsep momentum, impuls, dan tumbukan untuk mata pelajaran fisika SMA ini untuk memudahkan peserta didik dalam memahami konsep momentum, impuls, dan tumbukan melalui praktikum virtual dan bertujuan untuk membantu guru dalam proses pembelajaran yang dapat 
dijadikan sebagai media pembelajaran menggantikan alat peraga agar proses belajar mengajar lebih efektif dan efesien.

\section{Referensi}

Fidelia, Jennica. 2014. Laporan Praktikum Fisika Dasar Tumbukan. Surya University.

Nana, dkk. (2016). The Effectiveness of Scientific Approach Through Predict, Observe, Explain, Elaborate, Write and Evaluate (POE2WE). The Social Sciencer 11 (6), 1028-1034.

Nana. Model Prediction, Observation, Explanation, Elaboration, Write, dan Evaluation (POE2WE) Alternatif Pembelajaran Fisika di Era Revolusi Industri 4.0. Jurnal Pendidikan Fisika FKIP Universitas Siliwangi.

Nana, dkk. Pengembangan Pembelajaran Fisika SMA melalui Elaboration Write and Evaluation (EWE) dalam Kurikulum 2013. Disertasi Program Doktor Ilmu Pendidikan Fakultas Keguruan dan Ilmu Pendidikan Universitas Sebelas Maret.

Nana, Sajidan, Akhyar, M., \&
Rochsantiningsih, D. (2014). Pengembangan Pembelajaran Fisika SMA Melalui Elaboration Write and Evaluation (EWE) dalam Kurikulum 2013. Seminar Nasional Pendidikan Sains. [Online]. Tersedia: https://jurnal.fkip.uns.ac.id/index.php/sn ps /article/view/4944 [30 November 2019].

Nana, Sajidan, Akhyar, M., \& Rochsantiningsih, D. (2014). The Development Of Predict, Observe, Explain, Elaborate, Write, and Evaluate (Poe2we) Learning Model in Physics Learning At Senior Secondary School. Journal of Education and Practice. 5 (19): 59. [Online]. Tersedia: https://pdfs.semanticscholar.org/0369/d4 7537d64151743c19f76ddc81f5040255a9 .pdf [7 Desember 2019].

Darwono. 2017. Bijak Menggunakan Laboratorium Virtual. Kompasiana.com

Sa'idah, S. R., Prihandono, T., \& Wahyuni, S. (2018). Pengembangan Modul Momentum, Impuls, dan Tumbukan dengan Strategi Concept Mapping di Madrasah Aliyah Negeri. Pengembangan Modul Momentum, 78-84. 